\section{Jaydess audit standards and benefits}

Jaydess was introduced to UK users in 2014, but there are no recent publications regarding using Jaydess. We would like to share with readers the results of our Jaydess audit at ISH (integrated sexual health). We performed a retrospective audit of 20 women, who attended the ISH service for Jaydess insertion in 2016-17, analysing their electronic records in order to improve management of the patients with Jaydess. Two thirds of users were under the age of 25 years. It is important to provide patients with information regarding potential risk of developing low mood or/and depression with progesterone only contraception. Follow up (FU) is important as it reflects patient's satisfaction with Jaydess. We suggested improving the FU standard with a documented outcome. Our audit highlights a high rate of users under the age of 25 who are satisfied with Jaydess in 1 years' time. As a result, we would recommend promoting Jaydess in nulliparous patients group. Contraceptive choice is essential and based on risk assessment, especially in young nulliparous women. Prospective outcome of the audit is that nulliparous patients could benefit from Jaydess insertion. Cost savings is an important point. It is also cost effective, as Jaydess could be beneficial for patients planning to have children in 3 years, and cost effective for ISH services saving approximately $£ 20$ per patient compared with Mirena.

Jaydess was introduced to UK users in $2014,{ }^{12}$ but there are no recent publications regarding its use. We would like to share with Journal readers the results of our Jaydess audit in an integrated sexual health (ISH) service.

Jaydess is a $13.5 \mathrm{mg}$ levonorgestrel intrauterine system (LNG-IUS) and is licensed for 3 years for contraception only. Jaydess has a narrow inserter tube $(3.80 \mathrm{~mm}) .^{3}$ There are some similarities with the Mirena LNG-IUS. ${ }^{4}$ The Summary of Product Characteristics (SPC) states that Jaydess is not a first-choice contraceptive in nulliparous women due to its limited clinical use. $^{2}$ One of the benefits of Jaydess is its ease of insertion, being less painful to insert than a Mirena, but there have been no clinical publications comparing the two devices. Furthermore, Jaydess is more cost effective, with a National Health Service (NHS) price of $£ 69.22$ compared with $£ 88.00$ for Mirena (Levosert is $£ 66.00$ plus VAT, but has a wider introducer measuring $4.8 \mathrm{~mm}$ ).

We performed a retrospective audit of women who attended an ISH service in 2016-2017, analysing their electronic records in order to improve the management of the patients using Jaydess. A total of 20 patients with Jaydess insertion were identified: 13 (65\%) were under the age of 25 (range 17-24) years, including six (30\%) patients in the age group 17-20 years, seven (35\%) aged 21-24 years and seven (35\%) aged over 25 (range 31-42) years. Two-thirds of the users were aged under 25 years. All the women were asked about mental health issues, including depression and suicidal ideations, as contraceptive choice is essential and based on risk assessment, especially in young nulliparous women. With regard to parity, there were 17 (85\%) nulliparous women, including one 45 -year-old patient with stenosis of the endocervical canal, where Jaydess was the only choice of IUS in the ISH setting. There were two (10\%) multiparous women and one (5\%) woman was breastfeeding.

We would like to highlight the importance of checking silver allergy at counselling.

The follow-up rate was adequate at $75 \% \quad(n=15) \quad($ table 1$)$. One year following Jaydess insertion, 11 (65\%) patients were Jaydess 'keepers', five $(25 \%)$ did not return to the ISH as they had no problems with Jaydess, and two (10\%) patients had IUS reinsertions. In total, 18 (90\%) patients retained the Jaydess IUS. Regarding IUS reinsertions, one $(5 \%)$ patient with Jaydess reported IUS expulsion (a Mirena was reinserted at follow-up), and one (5\%) patient requested IUS reinsertion after having bleeding problems with Jaydess.

At follow-up we found that only two (10\%) patients requested Jaydess removal. One patient requested Jaydess removal after 1 month because she was going away and wanted to control her period with the combined oral contraceptive pill; a second patient requested removal after 3 months because of low mood, spotting and occasional discomfort. It is important to provide women with information regarding the potential risks of developing low mood and/ or depression with progesterone-only contraception.

In conclusion, the majority of the patients were happy with Jaydess: 16 $(80 \%)$ continued to use Jaydess and two (10\%) requsted IUS reinsertion.

As detailed in table 1, IUS standards were achieved for the majority of the 11 standard criteria.

Follow-up is important as it reflects patient satisfaction. We suggested

\begin{tabular}{|c|c|c|c|}
\hline Standard criteria & Patients (n) & Actual $(\%)$ & Target $(\%)$ \\
\hline 1 Counselling/discussion, including risk of infection, perforation, expulsion, pregnancy & 20 & 100 & 100 \\
\hline 2 Allergy and silver allergy checked & 20 & 100 & 100 \\
\hline 3 Sexually transmitted infection (STI) screening offered if appropriate & 20 & 100 & 100 \\
\hline 4 Antibiotics treatment offered if high risk of STI & N/A & N/A & 100 \\
\hline 5 Assistant present & 20 & 100 & 100 \\
\hline 6 Method of insertion documented & 20 & 100 & 100 \\
\hline 7 Bimanual examination performed and documented & 20 & 100 & 100 \\
\hline 8 Tenaculum application performed & 20 & 100 & 100 \\
\hline 9 Uterine sound performed and documented & 20 & 100 & 100 \\
\hline 10 Type of device, expiry number, batch documented & 20 & 100 & 100 \\
\hline 11 Follow-up/patient seen for review and outcome documented & 15 & 75 & 100 \\
\hline
\end{tabular}


improving the follow-up standards (table 1) with a documented outcome.

Our audit highlights a high rate of users under the age of 25 years who were satisfied with Jaydess at 1 year. As a result, we would recommend promoting Jaydess to nulliparous patients.

A prospective outcome of the audit is that nulliparous patients could benefit from Jaydess insertion. It is also a cost-effective method, and Jaydess could be beneficial for patients planning to have children in 3 years, saving approximately $£ 20$ per patient compared with Mirena.

\section{Lyubov Alexandrovna Matytsina-Quinlan 주}

East Cheshire Centre for Sexual Health (ECCSH), Macclesfield District General Hospital, Macclesfield SK10 3BL, UK

Correspondence to Dr Lyubov Alexandrovna Matytsina-Quinlan, East Cheshire Centre for Sexual Health (ECCSH), Macclesfield District General Hospital, Macclesfield SK10 3BL, UK; lyubov.matytsina@yahoo.com
Funding The authors have not declared a specific grant for this research from any funding agency in the public, commercial or not-for-profit sectors.

Competing interests None declared.

Patient consent for publication Not required.

Provenance and peer review Not commissioned; externally peer reviewed.

(c) Author(s) (or their employer(s)) 2019. No commercial re-use. See rights and permissions. Published by BMJ.

\section{Check for updates}

Published Online First 7 August 2019

BMJ Sex Reprod Health 2019;45:314-315. doi:10.1136/bmjsrh-2019-200308

\section{ORCID iD}

Lyubov Alexandrovna Matytsina-Quinlan http://orcid.org/0000-0003-3886-1036

\section{REFERENCES}

1 Melvin L, Scott J, Craik J, et al. Jaydess ${ }^{\circledR}$ levonorgestrel intrauterine system. J Fam
Plann Reprod Health Care 2014;40:1659.

2 Faculty of Sexual \& Reproductive Healthcare (FSRH). FSRH new product review: Jaydess ${ }^{\circledR}$ levonorgestrel intrauterine system LNG IUS (April 2014), 2014. Available: https://www.fsrh. org/standards-and-guidance/documents/ cec-ceu-newproductreview-jaydess-apr14/ [Accessed 2 Jul 2019].

3 Faculty of Sexual \& Reproductive Healthcare (FSRH). FSRH clinical guideline: intrauterine contraception (April 2015, amended October 2015), 2015. Available: https://www.fsrh.org/ standards-and-guidance/documents/ ceuguidanceintrauterinecontraception/ [Accessed 2 Jul 2019].

4 Faculty of Sexual \& Reproductive Healthcare (FSRH). UKMEC April 2016 (amended December 2017), digital version, 2016. Available: https://www. fsrh.org/standards-and-guidance/external/ ukmec-2016-digital-version/ [Accessed 2 Jul 2019]. 